\title{
Making Young Voters: The Impact of Preregistration on Youth Turnout
}

\author{
John B. Holbein Duke University \\ D. Sunshine Hillygus Duke University
}

\begin{abstract}
Recent research has cast doubt on the potential for various electoral reforms to increase voter turnout. In this article, we examine the effectiveness of preregistration laws, which allow young citizens to register before being eligible to vote. We use two empirical approaches to evaluate the impact of preregistration on youth turnout. First, we implement differencein-difference and lag models to bracket the causal effect of preregistration implementation using the 2000-2012 Current Population Survey. Second, focusing on the state of Florida, we leverage a discontinuity based on date of birth to estimate the effect of increased preregistration exposure on the turnout of young registrants. In both approaches, we find preregistration increases voter turnout, with equal effectiveness for various subgroups in the electorate. More broadly, observed patterns suggest that campaign context and supporting institutions may help to determine when and if electoral reforms are effective.
\end{abstract}

$\mathrm{E}$ ven within federal constraints, there remains considerable variation across states in the ease of voter registration. Political scientists have long debated the extent to which voter turnout might be fostered or hindered by various electoral rules, such as registration windows (Brians and Grofman 2001; Hanmer 2009; Keele and Minozzi 2013; Leighley and Nagler 2013; Neiheisel and Burden 2012), voter identification restrictions (Alvarez, Bailey and Katz 2008; Atkeson et al. 2010; Erikson and Minnite 2009; Mycoff, Wagner and Wilson 2009; Vercellotti and Anderson 2010), or online registration tools (Bennion and Nickerson 2011; Hanmer et al. 2010; Herrnson et al. 2008; Niemi et al. 2009; Ponoroff and Weiser 2010). While it was once commonly assumed that reducing legal obstacles to voting would inevitably lead to higher turnout (Burnham 1987; Lijphart 1997; Powell 1986; Wolfinger and Rosenstone 1980), more recent scholarship has challenged such optimistic conclusions, instead finding that electoral reforms often have little effect (Burden and Neiheisel 2013; Erikson and Minnite 2009; Keele and Minozzi 2013) or can even depress political engagement (Burden et al. 2014). As one scholar succinctly put it, "non-participants are not likely to flood the polls simply because registration barriers diminish" (Timpone 1998, 155).

An electoral reform that has nonetheless gained momentum in recent years is preregistration, whereby individuals younger than 18 are able to complete their registration application so that they are automatically added to the registration rolls once they come of age. Preregistration laws have been implemented in a dozen states, debated in at least 19 others in the last 5 years, and proposed in the U.S. Congress (2004). The policy is of particular salience and controversy in North Carolina, where preregistration was implemented with wide bipartisan support in 2009 and then abruptly repealed 4 years later by a newly elected Republican majority in the state legislature. ${ }^{1}$ Allegations swirled that the repeal was an attempt to impede future turnout among young voters, who had disproportionately voted Democratic in the 2012 election. ${ }^{2}$ On both sides of the aisle, policy makers seemed to assume that preregistration would increase youth

John B. Holbein is Ph.D. Student, Duke University, 238 Rubenstein Hall, Durham, NC 27708 (john.holbein@duke.edu). D. Sunshine Hillygus is Associate Professor, Department of Political Science, Duke University, 203 Gross Hall, Durham, NC 27708 (hillygus@duke.edu).

We wish to thank the National Science Foundation (Grant \#SES-1416816) for their generous support for this project. In addition, we wish to thank Barry C. Burden, Michael McDonald, Steven A. Snell, and three anonymous reviewers for their valuable feedback. Finally, we wish to thank Matthew Tyler for his invaluable work as a research assistant. Data and code for replicating our results can be found in the AJPS Data Archive on Dataverse (http://dvn.iq.harvard.edu/dvn/dv/ajps).

${ }^{1}$ In the North Carolina House of Representatives, 88\% of Republican members voted in favor of the preregistration bill in 2009; in 2013, $100 \%$ of Republican members voted for its repeal in a bill instituting a number of additional voting restrictions.

${ }^{2}$ See, for instance, "North Carolina Voter ID Law Targets College Students" in the Huffington Post (July 7, 2013) or "President Obama May Hit Political Turbulence in North Carolina Visit" in the Washington Post (January 14, 2014).

American Journal of Political Science, Vol. 00, No. 0, xxx 2015, Pp. 1-19

(C) 2015, Midwest Political Science Association

DOI: 10.1111/ajps.12177 
turnout; unfortunately, there have been no empirical evaluations of the effectiveness of preregistration laws. Furthermore, recent scholarly research evaluating other electoral reforms offers a rather bleak outlook for the potential to increase citizen engagement through institutional changes.

In this article, we estimate the causal effect of preregistration on youth turnout using two complementary approaches. First, using a nationally representative, pooled cross-section from the 2000-2012 Current Population Survey, we implement a difference-in-difference approach. We supplement this with lag models to create bracketed estimates of preregistration's impact (Angrist and Pischke 2008; Manski 1990). Second, focusing on the state of Florida, we leverage a discontinuity in preregistration rates based on date of birth, using fuzzy regression discontinuity models to estimate the effect of preregistration on future turnout. Whereas the first approach offers strong external validity, the second approach offers strong internal validity as to the estimated effect of preregistration. In both approaches, we find that preregistration has positive and significant effects on young voters' participation rates. From the difference-in-difference model, we find that preregistration laws increased turnout rates by $13 \%$, with the lag model indicating a lower bound of $2 \%$. From the regression discontinuity models, we find that, among those who comply by preregistering, voter turnout is about 8 percentage points higher than a comparable control group.

Our analysis also finds that preregistration increases turnout across a variety of subgroups, including by gender, race, and party. Most notably, preregistration is equally effective for Democratic and Republican registrants, with a net mobilization effect that actually slightly narrows the Democratic advantage among young voters. Beyond speaking to a timely policy debate, our results also offer a framework that helps to explain if and when electoral reforms might increase turnout. In contrast to other reforms, preregistration laws appear to leverage the malleability of political interest by targeting young citizens when they are in school and during the increased excitement, motivation, and mobilization of political campaigns. These results suggest that contextual factors and supporting institutions play an important role in determining the potential for electoral reforms to increase civic engagement.

\section{Background}

Political scholars and policy makers have long puzzled about the dismal participation rates of young Americans.
Since 18-year-olds were given the right to vote in 1972, there has been a persistent age gap in voter turnout. In $1972,50 \%$ of 18 - to 24 -year-olds voted compared to $70 \%$ of those age 25 and older; in 2012, this gap remained stubbornly high, with turnout levels at $41 \%$ and $65 \%$, respectively. ${ }^{3}$ The low turnout rates of young Americans have been attributed to a variety of factors. Some researchers focus on the lower levels of resources among young people that can impede participation (Wolfinger and Rosenstone 2006). Newly eligible voters may also be unfamiliar with the ins and outs of casting a ballot, including how and where to register to vote, making them more likely to miss registration windows or requirements (McDonald 2009). Even if these informational costs are small, they may deter some potential voters (e.g., Brady and McNulty 2011). Also, increased geographic mobility means young people are especially likely to incur these barriers repeatedly (Ansolabehere, Hersh and Shepsle 2006; Highton 2000; McDonald 2008).

Politicians, journalists, and policy advocates argue that preregistration reforms will increase youth turnout by reducing these voting costs (Cherry 2011). Preregistration laws allow citizens younger than 18 to add their names to registration rolls before they are eligible to vote, for instance, when applying for a driver's license. ${ }^{4}$ In introducing "The Gateway to Democracy Act" in the U.S. House of Representatives, Congressman Edward Markey (D-MA) made such an argument in his appeal for a countrywide preregistration law: "It is in the best interest of the country to make it as easy as possible for the youth of our nation to go to the polls for the first time....[The Gateway to Democracy Act] allows young people to take care of the paperwork ahead of time so that they don't have anything standing in their way on Election Day"5 (U.S. Congress 2004).

Despite the sanguine claims of preregistration proponents, there have been few attempts to empirically evaluate the effectiveness of preregistration laws. In the one exception, McDonald and Thornburg (2010) find

${ }^{3}$ Youth turnout rates were drawn from the Center for Information and Research on Civic Learning and Engagement's (CIRCLE) 2012 report on youth turnout: http://www.civicyouth. org/wpcontent/uploads/2013/05/CIRCLE'2013FS'YouthVoting 2012FINAL.pdf.

${ }^{4}$ Many states allow 17-year-olds who will turn 18 by Election Day to be added to the rolls when they are 17 . We, and others (McDonald and Thornburg 2010), make the distinction between this and preregistration, which allows young people to register even if they will not be eligible in the next election. Based on this distinction, Georgia and Iowa are not coded as preregistration law states in subsequent analyses.

${ }^{5}$ The bill was not voted out of committee. Senator Bill Nelson (D-FL) introduced a similar bill in the U.S. Senate in 2008. 
higher turnout rates in Florida and Hawaii among those who preregistered compared to those who registered after they turned 18 -preregistrants were $4.7 \%$ more likely to vote in the 2008 election than those who registered after they turned 18. Although consistent with the claim that preregistration increases turnout, the findings are far from conclusive. Looming is the issue of self-selection: Individuals who are especially interested in politics might be both more likely to preregister and more likely to vote. If so, then any relationship between preregistration and turnout is spurious, an artifact of unobserved levels of political interest, motivation, or propensity to vote. Indeed, this is a key explanation offered for the null findings that have become so common in causal analyses of the impact of other electoral reforms (e.g., early voting, vote-by-mail, Motor Voter registration). Although many classic observational works argued that burdensome registration requirements are "a major deterrent to voting" (Lijphart 1997, 7), this more recent causal research emphasizes that removing the obstacles to voting will not automatically translate into higher turnout among the unmotivated and unengaged (Ansolabehere and Konisky 2006; Berinsky, Burns and Traugott 2001; Burden et al. 2014; Burden and Neiheisel 2013; Hanmer 2009; Highton 1997; Keele and Minozzi 2013; Kousser and Mullin 2007; Leighley and Nagler 2013; Martinez and Hill 1999).

We contend, however, that there are distinct features of preregistration laws that should increase the likelihood the reform will be effective at increasing youth turnout. For a subset of the electorate, preregistration removes a barrier to participation when an individual is more likely to be interested in politics-during a political campaign (Freedman, Franz, and Goldstein 2004). That is, 16-year-olds who might not be eligible to vote in an election can nonetheless join the political system in the heightened salience of an electoral campaign. Once they are in the political system, other mechanisms may come into play. Being a part of the political system might, for instance, change a young person's identity as participant rather than outsider, which could in turn affect her efficacy, attentiveness, and, ultimately, participation in future elections (Bryan et al. 2011). Many scholars have concluded that there is a strong habitual nature of political engagement (e.g., Fowler 2006; Meredith 2009; Plutzer 2002), so earlier integration into the political system might set those forces in action. Indeed, the habitual nature of (non)voting might explain the diminishing impact of electoral reform returns found over the life course (Butler and Stokes 1974). Preregistration, in contrast, applies only to young citizens. To use the framework of Burden et al. (2014), preregistration is a reform that brings in new voters rather than retaining existing voters-making preregistration more like Election Day registration laws than early-voting laws. ${ }^{6}$

Preregistration is also reinforced by other supporting institutions. For example, most of the individuals who are eligible to preregister will be in high school, where they are likely to encounter a civics curriculum, in-school registration drives, or other reinforcing activities. There is a rich literature showing that exposure to a civics curriculum is related to turnout later in life (e.g., Niemi and Junn 2005). Some states mandate that election officials hold registration drives within public high schools (McDonald and Thornburg 2010). In addition, preregistration might be supported by campaign efforts (Burden et al. 2014). Once a young person is part of a state's voter file, she is more likely to be contacted by candidates, parties, and interest groups who use registration lists in targeting their campaign communications and mobilization efforts (Hillygus and Shields 2008).

In sum, there are several reasons to suspect that preregistration could be an effective reform for increasing turnout among young voters. More broadly, identifying these factors contributes to a conceptual framework for understanding when and if other electoral reforms should be effective. Political scientists have long explored the decision to vote through the lens of a voting calculus, focusing on cost reduction as a viable means of increasing turnout. In contrast, we start with the perspective that the cost of voting is not the only reason people stay home on Election Day. Rather than focusing on costs alone, we contend that effectiveness will also depend on surrounding contexts and other relevant institutions.

The empirical challenge is how to estimate an unbiased effect of preregistration given the powerful role of individual motivation in explaining turnout (Berinsky, Burns and Traugott 2001; Erikson 1981). Within the electoral reforms literature, many studies rely on statelevel "treatment" with a strong assumption about how electoral reforms originate (Erikson and Minnite 2009). This approach assumes that election reforms generate exogenously, outside the control of vested parties. These studies take variation in implementation as evidence of exogenous assignment. In this view, models need only control or match on observable traits. However, increasing evidence indicates that this approach can produce misleading results. Recent research argues that election laws are endogenous to political participation (Erikson and Minnite 2009; Hanmer 2009), either due to simultaneity (i.e., reforms result as responses to

\footnotetext{
${ }^{6}$ Indeed, Leighley and Nagler (2013) find that Election Day registration has quite large effects on the turnout of young voters but only minimal mobilization effects on older voters.
} 
turnout) or to complex, not well-understood networks of unobserved variables (e.g., motivation). For example, quasi-experimental studies of the impact of Election Day registration have shown marked differences to observational studies on the same topic (Keele and Minozzi 2013; Neiheisel and Burden 2012).

Our approach contributes to this broader literature by using a more compelling identification strategy to evaluate preregistration's impact. First, we examine the impact of preregistration across multiple states using a pooled cross-section. In this analysis, we combine difference-in-difference and lag models to bracket the aggregate effect of preregistration laws. We then narrow our focus to the state of Florida, where we are able to take advantage of a discontinuity in take-up of preregistration. In this part of the analysis, we use regression discontinuity models to estimate the causal impact of increased preregistration exposure among young adults in the voter file. This combination of approaches give us a complementary picture of the impact of preregistration on young voter turnout, and it provides an applied example of a methodological approach that others can use to evaluate the causal impact of state-level policies.

\section{Analysis 1: Current Population Survey}

We first draw from a pooled cross-section of the 20002012 Current Population Survey (CPS) to examine the effect of preregistration laws on turnout among young voters. The CPS gives us a large, nationally representative sample with coverage of both registered and nonregistered individuals with the biannual November Supplement.

As electoral reforms go, preregistration is relatively new, with most laws being adopted in the last 5 years. Table 1 shows the basic trends in voter turnout among young voters (18-22) from 2000 to 2012 for those states with preregistration laws in place. ${ }^{7}$ Boldfaced values indicate preregistration laws being in effect. For comparison, the final rows in the table show the average turnout rate of those states with preregistration and states without.

Table 1 offers suggestive evidence that preregistration might increase young voter turnout. Using the data in the table, two simple comparisons can be made. First,

\footnotetext{
${ }^{7}$ This age range offers ample statistical power as well as greater assurance that individuals were exposed to the preregistration treatment (wider ranges would include more individuals who would have been too old to utilize preregistration when implemented). As a robustness check, we estimated the models using other age cutoffs (e.g., 18-25, 18-29), with no change to our substantive conclusion.
}

TABLE 1 Turnout among Young Voters (CPS, 2000-2012)

\begin{tabular}{lccccccc}
\hline State & $\mathbf{2 0 0 0}$ & $\mathbf{2 0 0 2}$ & $\mathbf{2 0 0 4}$ & $\mathbf{2 0 0 6}$ & $\mathbf{2 0 0 8}$ & $\mathbf{2 0 1 0}$ & $\mathbf{2 0 1 2}$ \\
\hline Hawaii & $\mathbf{2 4 . 5}$ & $\mathbf{1 8 . 9}$ & $\mathbf{2 9 . 9}$ & $\mathbf{1 7 . 3}$ & $\mathbf{2 5 . 8}$ & $\mathbf{2 3 . 1}$ & $\mathbf{2 7 . 6}$ \\
Florida & $\mathbf{3 6 . 3}$ & $\mathbf{2 3 . 5}$ & $\mathbf{4 1 . 4}$ & $\mathbf{1 6 . 3}$ & $\mathbf{4 4 . 0}$ & $\mathbf{2 1 . 4}$ & $\mathbf{4 0 . 9}$ \\
Oregon & 42.5 & 27.7 & 55.7 & 36.0 & $\mathbf{5 3 . 4}$ & $\mathbf{3 4 . 5}$ & $\mathbf{4 8 . 0}$ \\
California & 30.0 & 18.3 & 35.6 & 20.3 & 40.5 & $\mathbf{2 4 . 0}$ & $\mathbf{3 7 . 7}$ \\
North Carolina & 38.6 & 21.4 & 45.3 & 19.2 & 52.1 & $\mathbf{2 3 . 4}$ & $\mathbf{5 0 . 2}$ \\
Rhode Island & 46.4 & 22.5 & 40.8 & 31.4 & 49.1 & $\mathbf{2 3 . 8}$ & $\mathbf{4 6 . 8}$ \\
DC & 52.7 & 31.1 & 54.8 & 32.0 & 65.0 & $\mathbf{3 1 . 9}$ & $\mathbf{6 1 . 9}$ \\
Maryland & 37.7 & 23.6 & 44.1 & 30.7 & 50.0 & $\mathbf{2 2 . 6}$ & $\mathbf{4 6 . 2}$ \\
Maine & 54.9 & 35.2 & 61.4 & 32.4 & 57.2 & 33.5 & $\mathbf{5 1 . 3}$ \\
Delaware & 44.1 & 18.7 & 46.8 & 24.3 & 48.4 & 28.9 & $\mathbf{4 3 . 4}$ \\
\hline Prereg. States & 36.1 & 22.5 & 42.6 & 23.5 & 46.0 & 25.3 & 43.3 \\
Other States & 40.9 & 25.4 & 47.6 & 26.9 & 47.8 & 24.7 & 43.8 \\
\hline
\end{tabular}

Note: Young voters are defined as those 18-22. States with preregistration laws in effect are boldfaced.

we can compare turnout patterns within preregistration states over time. Second, we can compare turnout patterns between preregistration states and nonpreregistration states. Combining these comparisons offers a very simple difference-in-difference estimate. Depending on which years are considered pre- versus posttreatment, the simple difference-in-difference estimates of preregistration's impact on young voter turnout are somewhere between 1.3 and 4 points. ${ }^{8}$ Of course, such a comparison is overly simplistic, likely subject to bias from aggregation or variables. For example, states like Oregon are surely different from Hawaii in systematic ways not accounted for in this basic comparison. A more compelling approach would attempt to account for such heterogeneities across states.

\section{Methods: Current Population Survey}

The pooled CPS data allow us to estimate both differences (across time and states) mentioned in the last section. In a difference-in-difference model, we are able to account for some unobserved variation, eliminating many sources of bias (Gelman and Hill 2007). State fixed effects can account for permanent characteristics of the state (e.g., persistent electoral institutions or social capital), year fixed effects for shared time trends (e.g., electoral context or national campaigns), and interactions between the

\footnotetext{
${ }^{8}$ With 2008 as pre and 2012 as post: $(43.3-46)-(43.8-47.8)=1.3$; with 2006 as pre and 2010 as post: $(25.3-23.5)-(24.7-26.9)=4.0$. If weighted, the impact from this simple comparison is somewhere between 0.0 (if 2008 is pre) and 5.1 points (if 2006 is pre).
} 
two for state-specific year effects (e.g., specific candidates or state-level campaigns). These fixed effects, when combined together, form a standard difference-in-difference model (Gelman and Hill 2007, 228). ${ }^{9}$

Difference-in-difference models are fairly standard in electoral reform studies (e.g., Burden and Neiheisel 2013; Fitzgerald 2005; Knack 1995; Leighley and Nagler 2013), as they offer a powerful antidote for many potential sources of bias left unaccounted for in cross-sectional models. Equation (1) shows the form of this model. The first difference in Equation (1) is between states with and without preregistration, and the second is before and after implementation.

$$
\begin{aligned}
Y_{i t}= & \lambda_{0}+\lambda_{p} P_{s t}+\lambda_{\alpha} \alpha_{s}+\lambda_{\delta} \delta_{t}+\lambda_{\gamma} \gamma_{s t} \\
& +\lambda_{X} X_{i t}+\epsilon
\end{aligned}
$$

In the model, the unit of analysis is the individual. The key predictor variable is an indicator of whether the respondent's state had a preregistration law in effect $\left(P_{s t}\right)$, and the outcome is whether the individual reported voting $\left(Y_{i t}\right) .{ }^{10}$ The analysis is restricted to young citizens, defined as individuals $18-22$ years of age.

To be sure, this model offers only a rough approximation of exposure to preregistration. For one, there is not a clear age threshold that should be used for the analysis since exposure to preregistration varies by age, state, and year. ${ }^{11}$ Second, individuals of the same age can have different opportunities to preregister or register regularly simply because of the nuances of date of birth and election timing-a fact we leverage in the next section of the article. Unfortunately, the CPS (and other comparable multistate data sources) includes age rather than date of birth in its public-use files, so we have a less precise exposure measure. Nonetheless, the model offers a reasonable approach for testing whether preregistration laws are related to aggregate changes in turnout among

${ }^{9}$ We use the terms "fixed effects models" and "difference-indifference models" interchangeably. Difference-in-difference models are "a special case of the ... fixed effects model" and are fitted "with a regression of the outcome on an indicator for the groups, an indicator for the time period, and the interaction between the two" (Gelman and Hill 2007, 228).

${ }^{10}$ Like others (Burden et al. 2014), we code voting as 1 if the individual indicated she voted in the most recent election and as 0 if she answered "no," "don't know," "refuse to answer," or has no response recorded.

${ }^{11}$ The exact age range exposed to preregistration varies across states and years, but there were always at least two states for which there were individuals in this age range exposed. For example, in 2008, only 22-year-olds in Hawaii and Florida would have been exposed to preregistration opportunities; in 2012, 18-year-olds in at least eight states had been exposed to preregistration. However, as we will show in subsequent sections, these borderline ages vary substantially in their exposure to preregistration. this age group. In other words, the estimated effects can be thought of as analogous to intent-to-treat rather than treatment-on-the-treated estimates (Bloom 1984).

Other model parameters for Equation (1) include $\alpha_{s}$ for the state fixed effects, $\delta_{t}$ for the year fixed effects, and $\gamma_{s t}$ for the full set of interactions between the two. Additionally $X_{i t}$, a matrix of time-varying controls, is included to absorb some time-varying heterogeneity. ${ }^{12}$ The $\lambda$ s represent the effect of preregistration and the other model components on turnout. To adjust for potential in-cluster correlations, we cluster our standard errors to the stateyear level. As is common, we report results from a linear specification of the dependent variable for simplicity in the interpretation of coefficients (e.g., Olken 2010). As fully reported in Table A1 in the supporting information, a probit specification yields similar (even stronger) results.

The difference-in-difference in Equation (1) accounts for a wide variety of potential biases. However, this approach has a key limitation: It is unable to control for unobserved time-varying factors (Ashenfelter and Card 1985). In examining the effect of preregistration, we might be worried that preregistration laws are endogenousstates with higher turnout could be more likely to implement preregistration because of pressure from vested constituencies, or perhaps states with attentive political elites might implement preregistration when youth turnout is particularly low. This would introduce simultaneity concerns that could bias difference-in-difference estimates of preregistration's impact on voter turnout. Indeed, this type of bias has increasingly troubled scholars of electoral reforms (Ansolabehere and Konisky 2006; Burden and Neiheisel 2013; Keele and Minozzi 2013).

Our approach goes one step beyond a differencein-difference in an attempt to address the endogeneity concern associated with time-varying unobservables. To do so, we complement our difference-in-difference with a set of models with lags. When used in separate, but similarly specified, models, the estimates from these two models can provide bracket estimates-a range of values in which the "true" effect falls (Angrist and Pischke 2008; Guryan 2004). ${ }^{13}$ Angrist and Pischke (2008) prove this formally, showing that fixed effects and lag models, when used together, "have a useful bracketing property"

\footnotetext{
${ }^{12}$ Controls mirror those in other electoral reform models (e.g., Burden et al. 2014) and include age, marital status, gender, family income, education status, race, registration status, metropolitan area, time at address, employment at a business or farm, the mode in which the CPS was administered, and whether an individual registered through the Department of Motor Vehicles (DMV).

${ }^{13}$ Lags should not be included in difference-in-difference models, as the error term and the lagged dependent variable are related through the lagged error term (Angrist and Pischke 2008, 245).
} 
assuming lagged outcomes or fixed characteristics are behind selection into treatment (Angrist and Pischke 2008, 246). When the relationship between the treatment and lagged dependent variable is positive, the fixed effects model sets the lower bound and the lagged model sets the upper bound. When the relationship is negative, the opposite is true (Angrist and Pischke 2008; Guryan 2004). While this approach has been applied in other disciplines, to our knowledge it has not been used in political science, despite the wide applicability to a wide range of state-level policy evaluations.

Thus, given potential concerns that the differencein-difference fails to account for endogenous variation in the adoption of preregistration laws, biasing the results upward, we can estimate the lower bounds of the preregistration effect using lag models. In Equation (2), we set aside the fixed effects and instead use a lagged turnout at the state level.

$$
Y_{i t}=\lambda_{0}+\lambda_{p} P_{s t}+\lambda_{Y} Y_{s, t-2}+\lambda_{X} X_{i t}+\epsilon
$$

Equation (2) is similar to Equation (1) in its unit of analysis, outcome, treatment, and controls. As in Equation (1), the preregistration treatment is at the state-year level, necessitating standard error adjustments. Although the unit of analysis in our model is an individual (with stateclustered standard errors), we do not have an individual's turnout in the previous election. Unfortunately, the CPS does not ask individuals about turnout across elections. Moreover, even if the CPS did have turnout measures across years, missing data would pose a significant problem in our application, as many young voters were not eligible to vote in the previous election. Thus, lagged turnout $\left(Y_{s, t-2}\right)$ is aggregated to the state level. ${ }^{14}$

In the next section, we report our difference-indifference and lag models, illustrating the bracketing property in our preregistration application.

\section{Results: Current Population Survey}

Table 2 reports the bracketed effects of preregistration laws on youth turnout rates, using the 2000-2012

\footnotetext{
${ }^{14}$ We use the lagged presidential election year turnout (2008). As a robustness check on our lower bound estimate, we estimated with all variables aggregated to the state level. Although this reduces the predictors to just state-level variables and reduces the sample size substantially, we are reassured by the fact that the state-level results remain supportive of our conclusion-a coefficient of .01 with $\mathrm{p}$-value of .09 ( $\mathrm{p}<.05$ in the baseline model with no controls).
}

TABLE 2 Voting, Bracketing Bias

\begin{tabular}{|c|c|c|}
\hline & $\begin{array}{l}\text { Diff./Diff. Model } \\
\text { (Upper Bound) }\end{array}$ & $\begin{array}{l}\text { Lagged Model } \\
\text { (Lower Bound) }\end{array}$ \\
\hline Preregistration State & $\begin{array}{c}0.13^{*} \\
(0.00)\end{array}$ & $\begin{array}{l}0.02^{*} \\
(0.01)\end{array}$ \\
\hline $\begin{array}{l}\text { State Lag Vote } \\
\text { (Same Election Type) }\end{array}$ & - & $\begin{array}{r}0.24^{*} \\
(0.04)\end{array}$ \\
\hline Age & $\begin{array}{r}-0.01^{*} \\
(0.00)\end{array}$ & $\begin{array}{r}-0.01^{*} \\
(0.00)\end{array}$ \\
\hline Married & $\begin{array}{r}-0.01 \\
(0.01)\end{array}$ & $\begin{array}{r}-0.01 \\
(0.01)\end{array}$ \\
\hline Female & $\begin{array}{r}0.01^{*} \\
(0.00)\end{array}$ & $\begin{array}{r}0.01^{*} \\
(0.00)\end{array}$ \\
\hline Family Income & $\begin{array}{l}0.003^{*} \\
(0.001)\end{array}$ & $\begin{array}{l}0.003^{*} \\
(0.001)\end{array}$ \\
\hline College Degree & $\begin{array}{c}0.08^{*} \\
(0.01)\end{array}$ & $\begin{array}{c}0.08^{*} \\
(0.01)\end{array}$ \\
\hline White & $\begin{array}{r}-0.02^{*} \\
(0.01)\end{array}$ & $\begin{array}{r}-0.02^{*} \\
(0.01)\end{array}$ \\
\hline Hispanic & $\begin{array}{r}-0.02^{*} \\
(0.01)\end{array}$ & $\begin{array}{r}-0.02^{*} \\
(0.01)\end{array}$ \\
\hline Registration Status & $\begin{array}{r}0.65^{*} \\
(0.01)\end{array}$ & $\begin{array}{r}0.65^{*} \\
(0.01)\end{array}$ \\
\hline Metropolitan Area & $\begin{array}{r}0.02^{*} \\
(0.00)\end{array}$ & $\begin{array}{r}0.01^{*} \\
(0.00)\end{array}$ \\
\hline Length of Residence & $\begin{array}{r}0.01^{*} \\
(0.00)\end{array}$ & $\begin{array}{r}0.01^{*} \\
(0.00)\end{array}$ \\
\hline Business/Farm & $\begin{array}{c}0.02^{*} \\
(0.01)\end{array}$ & $\begin{array}{c}0.02^{*} \\
(0.01)\end{array}$ \\
\hline In-Person Interview & $\begin{array}{r}-0.02^{*} \\
(0.00)\end{array}$ & $\begin{array}{r}-0.02^{*} \\
(0.00)\end{array}$ \\
\hline DMV Registration & $\begin{array}{r}-0.08^{*} \\
(0.01)\end{array}$ & $\begin{array}{r}-0.09^{*} \\
(0.01)\end{array}$ \\
\hline Constant & $\begin{array}{r}0.16^{*} \\
(0.03)\end{array}$ & $\begin{array}{c}0.04 \\
(0.03)\end{array}$ \\
\hline State Fixed Effects & Yes & No \\
\hline Year Fixed Effects & Yes & Yes \\
\hline State* Year Fixed Effects & Yes & No \\
\hline Number of Individuals & 44,821 & 44,821 \\
\hline Number of State-Years & 357 & 357 \\
\hline $\mathrm{R}^{2}$ & 0.53 & 0.52 \\
\hline
\end{tabular}

Note: Dependent variable is whether or not an individual reported voting. Sample is citizens, age 18-22, in the 2000-2012 CPS November Supplements. State lag vote is not included in the differencein-difference model, as the error term and the lagged dependent variable are related through the lagged error term (Angrist and Pischke 2008, 245). Cluster-robust standard errors (state-year level) are in parentheses $\left({ }^{*} \mathrm{p}<.05\right)$. 
Current Population Survey. ${ }^{15}$ Column 1 corresponds to Equation (1), the difference-in-difference model, and column 2 corresponds to Equation (2), the lag model. In both columns, the dependent variable is whether or not a young individual reported voting in the previous election.

The difference-in-difference model finds a substantial turnout impact from preregistration laws. ${ }^{16}$ That is, states that implement preregistration laws see an average 13 percentage point increase in the probability of voting among 18- to 22-year-olds compared to states without preregistration-a sizable mobilization effect compared to other electoral reforms (Ansolabehere and Konisky 2006; Burden and Neiheisel 2013; Hanmer 2009; Karp and Banducci 2000; Keele and Minozzi 2013). This analysis offers clear evidence that states that implement preregistration laws increase youth turnout in their states. Even our lower bound estimate indicates a positive and significant effect, though much smaller. Given the bracketing properties of the models, we can conclude that the true effect of preregistration reforms on youth voting is somewhere between $2 \%$ and $13 \%{ }^{17}$

Although this approach is better able to account for unobserved heterogeneities than a naive analysis between preregistration and turnout, it still has limitations. The treatment is rather crude, not able to cleanly identify who was exposed to preregistration. Though such models allow us to rule out some unobserved factors, they may not capture all unobserved heterogeneity (Keele and Minozzi 2013). We can never be certain that these models rule out all unobserved time-varying confounders or that lagged outcomes and fixed characteristics adequately describe selection into treatment. Put simply, even the most sophisticated panel techniques may not go far

${ }^{15}$ For the lag models, we include information from the 1996 and
1998 November Supplements.
${ }^{16}$ The model controls are generally in the expected direction and
are similar across models. When conditioning on all covariates,
education, income, registration status, and duration at address are
positively related to turnout, whereas DMV registration, requir-
ing an in-person interview to complete the survey, and age are
negatively related to turnout. Although age is typically positively
correlated with turnout, we had no a priori expectations about the
relationship for such a restricted age sample. Registration status
is included as a control to account for heterogeneity (by design)
between registered and unregistered citizens (Erikson 1981), but
the conclusions remain unchanged if we instead restrict our sample
to those who say they are registered.

${ }^{17}$ Our results are robust to alterations in our model specification. If we restrict our models to include only those who are registered, we find that preregistration increases turnout somewhere between 3.8\% (lag model) and $16.1 \%$ (difference-in-difference model). When weighted, the range is between $2.4 \%$ (lag model) and $14.3 \%$ (difference-in-difference model). enough to help us precisely estimate the impact of preregistration on youth turnout.

Thus, to address these limitations, we move from an across-state to a within-state comparison. By using the Florida voter file, we are able to generate a more precise measure of preregistration enrollments and can leverage a source of exogenous variation in preregistration exposure based on date of birth relative to Election Day. Such an approach trades the breadth of the analysis given in this section for a more rigorous, internally valid estimate that also hints at the potential causal mechanisms.

\section{Analysis 2: Florida Voter File}

In this alternative approach for estimating the effects of preregistration, we focus on the state of Florida for several reasons. First, Florida has had a preregistration law in place long enough to examine the potential impacts. For reasons that will become apparent below, our analysis requires a state to have had a preregistration law in effect through at least two election cycles. Second, unlike many other states, Florida's voter file contains full date of birth, which is necessary to precisely determine exposure to preregistration. ${ }^{18}$

Florida was the first state in the United States to implement a preregistration law. Since 1990, 17-year-olds could be added to the voter rolls, even if they would not be eligible to vote in the upcoming election. Since 2007, 16-year-olds have also been able to preregister. Take-up of preregistration has grown over time from about 10,000 (representing 10\% of 17-year-olds) in 1992 to about 60,000 (30\%) in 2004 (McDonald 2009). In the May 2013 voter file used for our analysis, approximately 300,000 of 4 million voters $(8 \%)$ had been added to the Florida voter file through preregistration.

In estimating the impact of preregistration on youth participation, we focus on turnout in the 2012 election among young Florida registrants $21-22$ years of age. ${ }^{19}$

\footnotetext{
${ }^{18}$ At the time of writing, only three states had preregistration laws in place for two presidential election cycles: Oregon, Hawaii, and Florida. Hawaii does not have date of birth in their voter files, eliminating it from potential consideration. Florida's voter file has birthdates for $99.95 \%$ of the sample. We selected Florida over Oregon because the unique vote-by-mail rules in Oregon might have undermined the generalizability of the results.

${ }^{19}$ We use the voter file as it was downloaded in May 2013. For the range of ages considered, purging is not an issue because four election cycles occur before an individual is purged, and our sample were eligible for three elections at most. In Florida, purging occurs only after a voter does not respond to a mailed verification and does not participate in three elections after failure to respond to the voter
} 
For this narrow age group, individuals can be divided into two seemingly arbitrary groups based on their date of birth relative to Election Day: those marginally eligible to vote in the 2008 election (17 turning 18 by November 4,2008 ) and those marginally ineligible. We use this discontinuity in date of birth as a sorting mechanism that assigns individuals to treatment and control groups (with some noncompliance) in an as-good-as-random fashion. These two groups are similar on a great many characteristics but differ as to whether they had the opportunity to preregister during the 2008 campaign. To be clear, marginal eligibles also had the opportunity to preregister, but that chance occurred outside the context of an election. These slightly older individuals were able to register regularly during the 2008 campaign. Thus, our sample consists of young adults in the 2012 Florida voter file who were marginally eligible or ineligible to vote in 2008. Our treatment is eligibility to preregister during the 2008 campaign; our control is eligibility to register regularly during the same time period.

Figure 1 shows the resulting variation in preregistration rates graphically, across birthdays, for those individuals in a 6-month window on either side of the eligibility to vote cutoff (November 4, 1990-marked by dashed line). Those to the left of the cutoff were marginally eligible to vote in 2008 . Those to the right were marginally ineligible in 2008. A local linear regression (black line) on either side of the cutoff is displayed to show the trend in preregistration enrollment around the cutoff, and the individual observations are plotted as sunflowers.

Figure 1 shows two things: First, a clear discontinuity exists in preregistration rates at the eligibility to vote cutoff, and second, it is substantial. According to local linear models, marginal ineligibles were nearly 40 percentage points more likely to have preregistered than marginal eligibles. ${ }^{20}$ Simply put, we see that those (just barely) too young to vote in 2008 often preregistered, whereas those (just barely) old enough to vote were usually brought in via traditional registration.

As can also be seen in the graph, there is some noncompliance in our sample-those who are marginally ineligible sometimes wait until they are older to register regularly (most of our noncompliance comes from this behavior; notice the abundance of observations in the lower right corner of the graph), and those who are marginally eligible sometimes preregister long before

verification. Our sample was eligible to vote in three elections at most (marginal eligibles).

${ }^{20} \mathrm{~A}$ similar discontinuity is observed in the 2008 voter file, in which the percentage of individuals preregistering in the 2004 election was about $30 \%$ higher among marginal ineligibles than marginal eligibles (see Figure A2 in the supporting information). the election, when they are 15 or 16 , again outside of a campaign context. A simple cross-tabulation shows that noncompliance composes about $30 \%$ of our sample. Nonetheless, on average, marginal ineligibles are much more likely to preregister than marginal eligibles. In other words, individuals marginally ineligible are exposed to an increased dosage of preregistration simply based on their date of birth relative to Election Day many years later. This difference forms the essence of our identification strategy.

Why does this discontinuity exist? We expect the timing in which elections occur in one's life course is likely key. Campaigns and elections encourage registration. When an election approaches, both marginal ineligibles and eligibles are exposed to the overall excitement surrounding an election and the corresponding campaign information, events, and activities. The sum result is that many will enter the political system at this time. Preregistration laws simply make it possible for younger people to do so.

\section{Methods: Florida Voter File}

To estimate the impact of preregistration on turnout, we use a fuzzy regression discontinuity approach. This approach is required as compliance is not $100 \%$ : Those who are marginally ineligible sometimes wait until they are older to register regularly, and those marginally eligible sometimes preregister. ${ }^{21}$ Still, as we saw in Figure 1, there is a discrete jump at the eligibility cutoff. So long as the eligibility discontinuity is as-good-as random, this approach will produce estimates of preregistration's mobilizing power that are free of omitted variable bias (from observables and unobservables) and simultaneity (Lee and Lemieux 2010).

Fuzzy regression discontinuity utilizes an instrumental variables approach, with the sorting rule (eligibility to vote in 2008) serving as an instrument of the treatment behavior (preregistration). Equations (3) and (4) show the two-stage form of this approach, common to those familiar with two-stage least squares. ${ }^{22}$

$$
\begin{aligned}
& P_{i, 2008}=\gamma_{0}+\gamma_{1} I_{i, 2008}+\gamma_{2} R_{i, 2008}+\epsilon \\
& Y_{i, 2012}=\beta_{0}+\beta_{1} P_{i, 2008}+\beta_{2} R_{i, 2008}+\delta
\end{aligned}
$$

\footnotetext{
${ }^{21}$ This approach was pioneered by Trochim (1984) and has been increasingly used in public policy, economics, and political science (e.g., Burden and Neiheisel 2013; Eggers and Hainmueller 2009; Ferraz and Finan 2009).

${ }^{22}$ As is done in other applications, we use ordinary least squares (OLS) with a binary dependent variable for simplicity in interpretation (e.g., Olken 2010). The results do not change with probit regression (see Table A4 in the supporting information).
} 


\section{FIGURE 1 Fuzzy Preregistration Treatment}

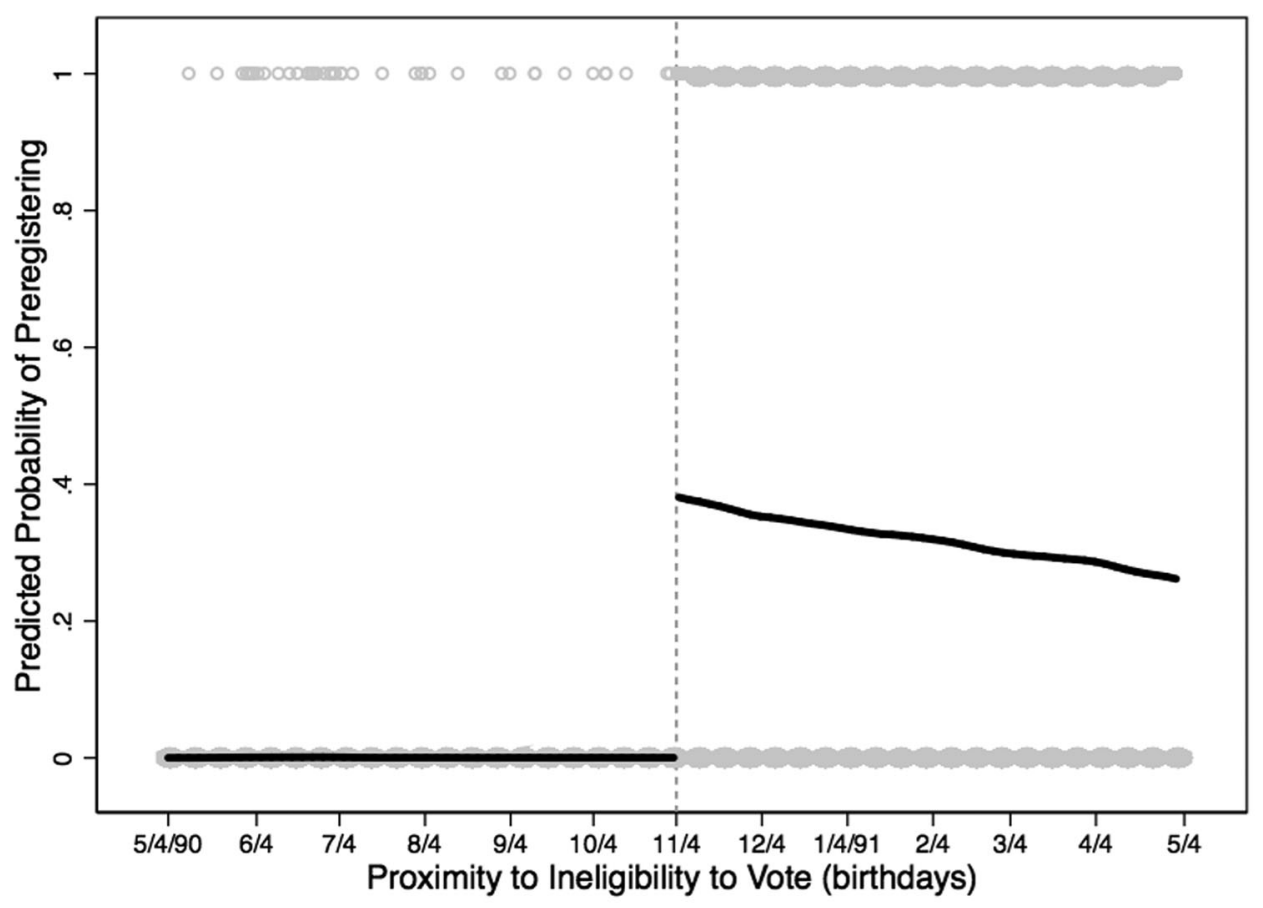

Note: The figure plots the predicted probability of preregistering, across birthdays, for individuals in the 2012 Florida voter file within the 6-month window on either side of 2008 voter eligibility cutoff (November 4, 1990). Those to the left of the cutoff are marginally eligible. Those to the right are marginally ineligible. Individual observations ( 1 if preregistered, 0 if not) are plotted as sunflowers, with each representing between 1,000 and 10,000 individuals and dots representing between 1 and 999 cases.

Equation (3) displays the first stage. In it, ineligibility to vote in $2008\left(I_{i, 2008}\right)$ and our running variable, proximity to ineligibility $\left(R_{i, 2008}\right)$, predict whether an individual preregistered in $2008\left(P_{i, 2008}\right){ }^{23}$ The $\gamma s$ in this equation represent first-stage parameter estimates, with $\gamma_{1}$ revealing the estimated difference in preregistration rates between marginal ineligibles and marginal eligibles (on average).

Equation (4) displays the second stage. In it, the influence of preregistration in $2008\left(P_{i, 2008}\right)$ on voter turnout in the next presidential election $\left(Y_{i, 2012}\right)$ is estimated. It is important to note that we observe whether individuals ever preregister during their window of opportunity to do so. Thus, we can estimate not only the impact of offering preregistration (intent to treat [ITT]) but also the effect of preregistration take-up (treatment on the treated [TOT]). Thus, the coefficient of interest in our models is $\beta_{1}$ (for the TOT) and the

\footnotetext{
${ }^{23}$ In our application, the proximity variable is how close individuals' birthdays put them to ineligibility to vote in 2008 . Positive numbers indicate ineligibility to vote (and thus receive the preregistration treatment); negative numbers indicate eligibility. Note here that the running variable is modeled linearly.
}

coefficient on $I_{i, 2008}$ when it is substituted into the second stage and run in a normal OLS model (for the ITT).

We have estimated a number of variations to the model specification. For example, the proximity parameter has been modeled up to a quintic polynomial. ${ }^{24}$ In other models, we specify proximity as nonparametric, allowing additional flexibility in estimating the effect of preregistration at the cutoff. We have also estimated alternative standard error adjustments: clustering by county, precinct, birthday, and birth week and various bootstrapping procedures. Our models have also been estimated with and without controls and fixed effects. All these approaches yield substantively identical results. That our models are robust to these variations in model specifications is further evidence of the strength of our discontinuity as a valid sorting mechanism (Imbens and Kalyanaraman 2012; Lee and Lemieux 2010).

\footnotetext{
${ }^{24}$ Specifically, we have checked whether linear, quadratic, cubic, quartic, and quintic parameterizations of the running variable change our estimates of the effect of preregistration. Modeling the running variable in these ways does little to our result (see Table A7 in the supporting information).
} 
Specification Checks. In comparing our treatment (marginal ineligibles), to our control group (marginal eligibles) we need to establish that the discontinuity is valid - that is, that our cutoff sorts people in an as-goodas-random manner (Imbens and Kalyanaraman 2012; Lee and Card 2008; Lee and Lemieux 2010). This assertion may be challenged if the discontinuity can be precisely manipulated or treatment at the margin is confounded by some alternative factor. To check for the presence of these violations, we implemented a set of standard checks suggested in the regression discontinuity literature: a test for covariate balance at the cutoff, the McCrary density test for precise sorting of the discontinuity, and an informal placebo test for jumps at points other than our discontinuity (Lee and Lemieux 2010; McCrary 2008). The supporting information offers a more thorough discussion of these results. However, we mention here that our discontinuity appears valid across all suggested tests. For example, on covariate balance-a critically important test for the assumption of local randomization-we find balance at the eligibility cutoff in race, education, marital status, poverty, income, population, religiosity, and presence of an Obama field office in the county. ${ }^{25}$

Another concern might be less with the assignment of treatment and control than with interpretation of the treatment effect. If a treatment other than preregistration varies at the same cutoff, our results could be misattributed. Although we know of no institutional cutoff that shares the November 4 cutoff, our treatment and control groups differ in two fundamental ways besides whether or not individuals preregistered. ${ }^{26}$ First, the control group is slightly older than the treatment group. This is, of course, by design since age defines our treatment condition. Second, individuals marginally ineligible to vote in 2008, (those treated with the opportunity to preregister) obviously could not vote in 2008 , whereas the control group could, and thus may have developed more of a habit for voting (Meredith 2009). We more explicitly evaluate this concern later, but simply note here that both of these differences would likely bias our results downward because of expectations that a slightly older, more politically experienced control group would vote at higher rates than our treatment group. This would suggest our results are a

\footnotetext{
${ }^{25}$ The only exceptions-partisanship and gender-are substantively small and included in subsequent models. See Table A2 in the supporting information for the full set of comparisons.

${ }^{26}$ We do not observe discontinuities in the probability of preregistration or in our outcome for any given random point on our forcing variable not at the eligibility cutoff. The cutoff for eligibility to enter school occurs within our window (on September 1, 1990), but not at the margin for eligibility. When we control for the school eligibility cutoff, our results do not change.
}

conservative estimate of preregistration's impact on youth turnout.

Finally, we should emphasize that our treatment effect is localized to the time frame studied. That is, we cannot separate out the effect of being eligible to preregister from the effect of being eligible to preregister within the context of a presidential campaign-a critical point we return to in the conclusion.

\section{Results: Florida Voter File}

Table 3 shows our results. The model controls for a variety of pretreatment factors both at the individual and geographic levels (control coefficients are reported in Table A1 in the appendix). Reassuringly, the estimated effect is not sensitive to the controls included. This suggests that even where covariates are not balanced, it does not change the estimated effect beyond influencing precision.

The estimates in Table 3 are based on a regression discontinuity model with a linear parameterization of the running variable (proximity to the cutoff) and a 2-month bandwidth. The bandwidth refers to the range of data around the cutoff that is included in the analysis; in this case, a 2-month bandwidth indicates that the treatment group includes those born in the month before November 4, 1990, and that the control group includes those born on or in the month after that date. Reported in column 1 is the ITT estimate of preregistration's effect on voter turnout-that is, the effect of offering preregistration, not accounting for program take-up. It is equivalent to estimating Model (4), substituting ineligibility $I_{i, 2008}$ for the preregistration variable.

The model in column 1 indicates that the effect of offering preregistration on young voter turnout is a $3 \%$ bump, on average, in the probability of voting. Noticeably, this estimate is in the bracketed range from the CPS model estimates provided in a previous section. The TOT, reported in column 2, takes into account take-up of treatment, estimating the effect of preregistration on turnout among compliers. In our case, compliers are those who (1) were ineligible to vote in 2008 and preregistered and (2) were eligible to vote in 2008 and registered regularly. Noncompliers are the others who (1) were eligible to vote in 2008 and preregistered at an earlier date (2) were ineligible to vote in 2008 and registered regularly at a later date.

The results show that the effect of preregistering among compliers was to increase the probability of voting by $8 \%$ on average. As discussed in the next section, the 
TABLE 3 Florida Regression Discontinuity Estimates

\begin{tabular}{lcccc}
\hline & $\begin{array}{c}\text { ITT } \\
(\mathbf{2 0 0 8})\end{array}$ & $\begin{array}{c}\text { TOT } \\
(\mathbf{2 0 0 8})\end{array}$ & $\begin{array}{c}\text { ITT: Fixed Effects } \\
(\mathbf{2 0 0 4} \text { and 2008) }\end{array}$ & $\begin{array}{c}\text { TOT: Fixed Effects } \\
(\mathbf{2 0 0 8})\end{array}$ \\
\hline Preregistration & $0.03^{*}$ & $0.08^{*}$ & $0.02^{*}$ & $0.08^{*}$ \\
Controls & $(0.01)$ & $(0.03)$ & $(0.01)$ & $(0.03)$ \\
Fixed Effects & Yes & Yes & Yes & Yes \\
Constant & No & No & Birthday & County \\
& 0.048 & 0.083 & -0.024 & $0.56^{*}$ \\
F-Weak Instruments & $(0.088)$ & $(0.089)$ & $(0.058)$ & $(0.08)$ \\
Mean squared error & - & 2,963 & - & 2,966 \\
$\mathrm{~N}$ & 0.24 & 0.24 & 0.24 & 0.24 \\
& 36,790 & 36,790 & 71,251 & 36,790 \\
\hline
\end{tabular}

Note: Robust standard errors are in parentheses. Estimates are based on a 2-month window and a linear specification of the running variable. Controls: race (individual and county), party, gender, proportion of population that graduated high school (county), poverty (county), voter turnout (county), median age (county), and an indicator for the Democratic presidential party having a campaign office in the county. Coefficients for these are included in Table A1 in the appendix. ${ }^{*} \mathrm{p}<.05$.

effect size remains in the same vicinity across alternative specifications of the running variable and bandwidth, with coefficients not being statistically distinct from each other but statistically different from 0 at the $95 \%$ level. In addition, we estimate the TOT model with county fixed effects to account for unobserved variation that is constant over time (column 4 in Table 3 ). If our effect were driven by county differences at the cutoff, we would expect our TOT effect to disappear in this fixed effects model. It does not-adding county fixed effects to this model has little impact on the results.

Figure 2 offers a visualization of the overall causal effect of preregistration on turnout. Notice in Figure 2 the jump in the plotted line at the eligibility cutoff. Elsewhere on the graph, the slope of the smoothed function is relatively flat: Generally, turnout varies smoothly across birthdays, offering an informal placebo test. If there had been jumps in turnout at other points, our preregistration effect could be capturing these patterns rather than the true effect of preregistration. However, we see that other than at the eligibility discontinuity, voters born on different days tend to vote at relatively similar levels.

Robustness Checks. As described above, comparing our control group (marginal eligibles) to our treatment group (marginal ineligibles) within a narrow range around the treatment cutoff (ineligibility to vote) allows us to look at the impact of exogenous variation in preregistration on turnout. However, in regression discontinuity applications, the bandwidth - or range of data around the discontinuity that is used to estimate the treatment effect-is not well defined (Lee and Lemieux
2010). Put differently, we do not know how many days (i.e., how much of our sample) to include on either side of the discontinuity. It is thus valuable to estimate the model across a variety of bandwidths.

Figure 3 visually illustrates the results of varying the bandwidths. On the horizontal axis, we plot different bandwidths used to estimate preregistration's coefficient (the bandwidth is always split evenly on both sides of the discontinuity). On the vertical axis, we plot the estimated effect of preregistration on turnout.

Figure 3 illustrates that our results hold across different bandwidths. Estimates with more data support should be more precise, but less accurate; estimates with less data support should be less biased, but less precise. Only when we reduce our bandwidth to 24 days ( 12 days on either side of the discontinuity) does our estimated effect fall below traditional levels of statistical significance $(\mathrm{p} \approx .081)$. However, the estimated coefficient remains in the same neighborhood as previous estimates. ${ }^{27}$ Losing significance at this level is likely a power issue. This consistency across multiple bandwidths is further evidence that the preregistration effect is robust to varying components of the model. Moreover, this analysis offers reassurance that our results are not an artifact of a minor change in the Florida law in $2007 .{ }^{28}$

\footnotetext{
${ }^{27}$ Imbens and Kalyanaraman (2012) propose an algorithm for selecting a bandwidth based on minimizing mean squared error. In our application, this algorithm would result in a bandwidth of 241 days. The results are reported for this bandwidth in the supporting information (see Table A6), but we are able to use an even narrower (and thus more rigorous) bandwidth given the consistency in effects across bandwidths.

${ }^{28}$ Most individuals in our sample (75\%) were exposed to the preregistration law as it was written in 2007 , allowing them to preregister
} 


\section{FIGURE 2 Preregistration's Effect}

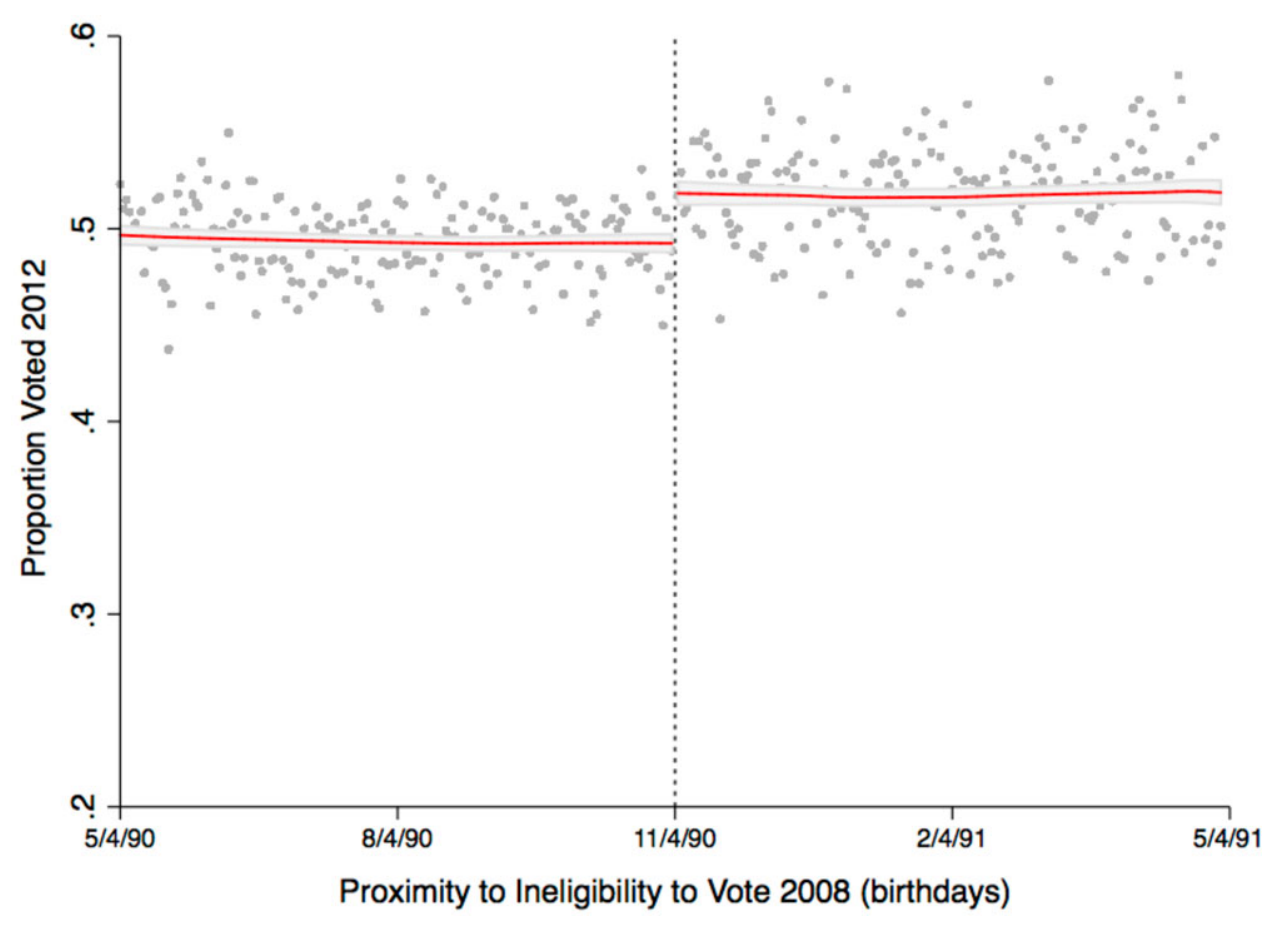

Another potential concern might be that the 2008 election was exceptional in terms of youth engagement. As a check, we add another election year to our analysis, estimating our regression discontinuity models using data from marginal eligibles/ineligibles who came of age in 2004 to estimate the impact on turnout in the subsequent presidential election. ${ }^{29}$ This approach has the added virtue of being able to add birthdate fixed effects to our regression discontinuity models, absorbing other potential confounders at our cutoff that vary systematically across elections. For example, if there were concerns that parents might plan births around the eligibility to vote cutoff (as has been seen around tax year

when they were 15-17 (youth ages 15-16 needed a driver's license to do so). The younger end (15\%) was exposed to the slightly looser preregistration laws under a law change in 2008 (no driver's license restriction). Older individuals in our sample were exposed to an earlier version of the law, allowing only 17 -year-olds to preregister $(10 \%)$. In Figure 3, the bandwidths from 0 days to 120 days were exposed to the 2007 law. Bandwidths from 120 to 332 days include the 2008 law (only for those born later). Bandwidths wider include the pre-2007 law (only those born earlier). As can be seen in Figure 3, our results do not change across these minor variations in the law.

${ }^{29}$ For the additional election year analysis, we rely on the November 4,2008 , voter file. This ensures that our results are not an artifact of purging that might have occurred by 2012 . cutoffs), a panel component could account for this. ${ }^{30}$ If this or any other unobserved time-invariant factors were driving our results, then adding the birth year fixed effects would wash out the result.

As with our previous analysis, we see a jump in preregistrations at the 2004 eligibility cutoff $(\approx 30 \%$ increase in preregistration enrollments for marginal ineligibles). ${ }^{31}$ Thus, the discontinuity we observe in 2008 is not unique to that year, suggesting a broader trend in preregistration rates. $^{32}$ Because preregistration differs across years, we cannot estimate a comparable TOT. However, we can estimate an ITT effect (the effect of being marginally ineligible, regardless of preregistration take-up). This model is equivalent to combining a difference-in-difference with our regression discontinuity models. In this model, the first difference is between marginal ineligibles (preregistration eligible) and marginal eligibles (regular

\footnotetext{
${ }^{30} \mathrm{~A}$ birthday fixed effect would account for this as long as this behavior was consistent for a given birthday from one election to the next.

${ }^{31}$ When we use this discontinuity alone to estimate the effect of preregistration in 2004 on turnout in 2008, we get an ITT of approximately $1 \%$ and a TOT of approximately $3 \%$. That these sizes are smaller makes sense given the smaller population allowed to preregister in 2004 relative to 2008 (McDonald 2009).

${ }^{32}$ This point is illustrated in a graph of preregistration rates by date of birth across both election years available in the supporting information (see Figure A2).
} 
FIGURE 3 Varying Bandwidths

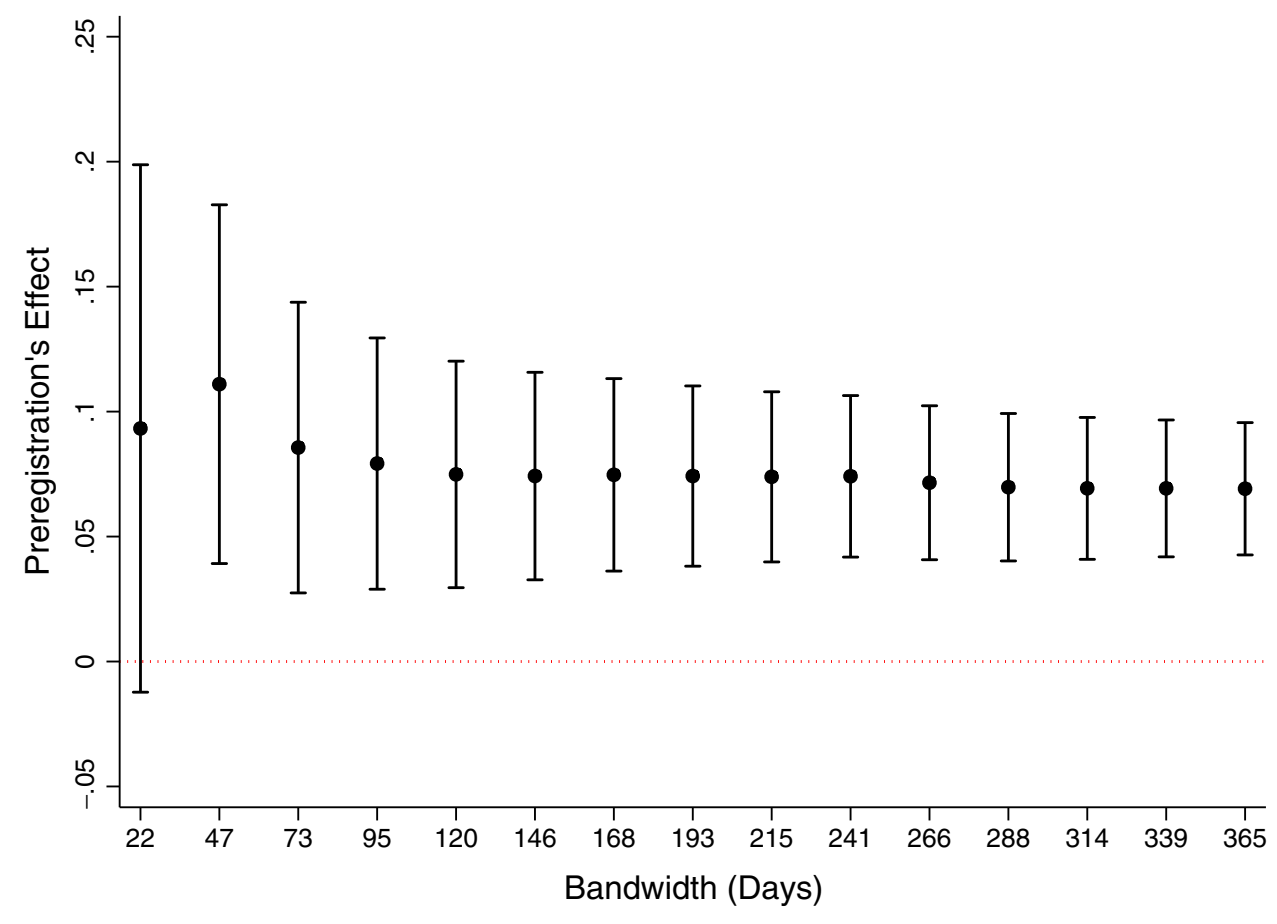

registration eligible). The second difference is between those in 2004 versus 2008, removing any time-invariant potential biases. Equation (5) displays the form of this regression discontinuity, difference-in-difference model.

$$
\begin{aligned}
Y_{i, \alpha}= & \gamma_{0}+\gamma_{1} I_{i, \lambda}+\gamma_{2} 2008_{i}+\gamma_{3}\left(2008_{i} * I_{i, \lambda}\right) \\
& +\gamma_{4} R_{i, \lambda}+\epsilon
\end{aligned}
$$

In Equation (5), the outcome remains whether or not the individual turned out to vote in the first subsequent presidential election $\left(Y_{i, \alpha}\right)$. For those who were marginally eligible/ineligible in 2004, we considered their turnout in $2008(\alpha=2008)$. The model includes an indicator for marginal ineligibility $\left(I_{i, \lambda}\right)$ and proximity to ineligibility $\left(R_{i, \lambda}\right)$ for those both in 2004 and $2008(\lambda=2004$ or $\lambda=2008$ ). Also included is an indicator for whether or not the individual was a marginal eligible/ineligible in 2004 or $2008\left(2008_{i}\right)$. The variable of interest in Equation (5) is the interaction between eligibility in 2008 and being ineligible to register. The coefficient on this interaction term $\left(\gamma_{3}\right)$ shows the ITT effect of being offered preregistration, holding constant things that remained fixed over time. This combined regression discontinuity, difference-in-difference model offers a powerful antidote for possible omitted variables involved with birthday discontinuities (Jacob and Lefgren 2004).

The results of this robustness check are reported in column 3 of Table 3 . This model produces a similar result to that in column 1, offering powerful evidence that our results are not driven by unobserved time-invariant factors or the uniqueness of the 2008 election. Offering preregistration increases turnout by approximately $2-3 \%$ among registrants coming of age during the 2004 and the 2008 campaigns.

Returning to our 2012 sample, a final issue to address involves differences between our treatment and control groups in their eligibility to vote in the 2008 election. Our results show that those who were marginally ineligible are more likely to vote in subsequent elections than marginal eligibles. This result may seem counterintuitive because marginally eligible individuals had the opportunity to vote in the 2008 election, whereas marginally ineligibles did not. Given the habitual nature of voting (Fowler 2006; Meredith 2009; Plutzer 2002), we might expect the opposite- that our control group, with more voting experience (on average), would also vote at higher rates in the subsequent election (on average). ${ }^{33}$ An ideal control group would have comparable levels of habit for voting with our treatment group, but that is not possible since our identification strategy specifically utilizes the exogenous jump in preregistration at the eligibility discontinuity in order to draw causal inferences.

\footnotetext{
${ }^{33}$ To be clear, our results are not necessarily inconsistent with the research on habitual forces given our narrow age range and limited geographic area (in a preregistration state).
} 
Additionally, no other useful discontinuities exist: Exogenous jumps in preregistration are not abundant. ${ }^{34}$

Though an imperfect solution, we can at least identify the likely sign of potential bias from such an effect. Again, many might expect that our slightly older, more experienced control group would be more likely to vote than our less experienced treatment group-biasing our estimates of preregistration downward. As a check of the likely downward bias induced by habit for voting, we use as a control group individuals who were marginally eligible but did not vote in 2008. By not participating, these individuals were unlikely to establish a habit for participating in the political process, thus not receiving a potential habit for voting treatment. To be clear, voting in the 2008 election is not randomly assigned, and there is little doubt that those who did not vote in 2008 are inherently different from those who voted. Even still, this approach provides us with an empirical check of the theorized effect habit has on our estimates.

Table 4 displays the results from this rough test, replicating these purged models alongside our original results. The first and third columns replicate estimates from Table 3, for comparison. The second and fourth columns display similar models, using only individuals who did not vote in 2008 in the control group. The results support the hypothesis that habit would likely bias our results downward. With habitual voting purged in this way, preregistration increases turnout no more than $14 \%$ and no less than 3\%. For compliers, preregistration's mobilizing effect ranges between $8 \%$ and $35 \%$. These results offer reassurance that - if anything — our previous results underestimated the impact of preregistration on youth turnout due to the habitual nature of voting.

To summarize, then, across a variety of model specifications, our results consistently show a noticeable increase in the probability of voting for those exogenous nudged toward preregistration. This result holds regardless of how the running variable is specified, what controls are included, what bandwidth is used, what years are included, or whether habit for voting is considered. The results consistently point to the conclusion that preregistration is effective at increasing turnout among young voters.

\footnotetext{
${ }^{34}$ Two other cutoffs without the habit treatment seem appealing. First, cutoffs on the young end of our sample, comparing those who were eligible to preregister in an election versus not, are confounded by preregistrations in subsequent elections. Second, a discontinuity does exist at the May 21, 1990, cutoff (corresponding with those affected by the 2007 law change versus not), but the law change appeared to be so minor that treatment at this margin is relatively weak - this cutoff allowed preregistration among 15- to 16-yearolds, but the majority of preregistration occurs at age 17 .
}

\section{Heterogeneities}

In previous sections, we have attempted to address whether preregistration mobilizes young voters. Our evidence suggests that it does, and noticeably so. However, also of substantive interest is who among young voters is mobilized by preregistration. Here we explore several possible individual-level heterogeneities in those effects (see the supporting information for full results). ${ }^{35}$

As highlighted by the North Carolina controversy mentioned in the introduction, there has been speculation that preregistration laws are especially likely to benefit Democratic candidates. To test this possibility, we reran our regression discontinuity model (from Figure 2), stratifying on party registration. We find that the effects of preregistration are quite similar for young Democrats and young Republicans. Preregistration increased turnout by about 7.6 points among Democrats and 7.4 points among Republicans-differences that are not statistically different from one another.

Democrats benefit more in the absolute number of votes from preregistration compared to Republicans simply because there are more registered young Democrats than young Republicans ( $42 \%$ versus 25\% among 18 -year-olds in the voter file); however, in contrast to popular assumptions, our results suggest that preregistration actually helped Republicans to slightly narrow the Democratic advantage among young people because the mobilization effect gap is smaller than the party voting gap. A back-of-the-envelope calculation helps to illustrate this point. We estimate that approximately $37 \%$ of partisan voters mobilized by preregistration in 2008 were likely to vote Republican in 2012; in comparison, only $32 \%$ of young voters in Florida voted Republican in $2012 .{ }^{36}$ In other words, in terms of net mobilization, preregistration appears to slightly advantage Republicans. This pattern is quite consistent with previous studies that have found institutional programs tend to register more Democrats (Herron and Smith 2012) but mobilize more Republicans (Cain and McCue 1985; Neiheisel and Burden 2012).

In addition to partisan heterogeneities, we consider possible differences in preregistration effects across race and gender-additional subgroups of interest to political

\footnotetext{
${ }^{35}$ Given the reduction in sample size that comes with stratification, results are calculated using a bandwidth of 241 days based on the Imbens and Kalyanaraman (2012) algorithm.

${ }^{36}$ Voters Mobilized by Preregistration $=(\%$ Mobilized $*$ \# in Base $)-$ (\% Crossover $* \%$ Mobilized $* \#$ in Base). For Democrats: $(.076$ $* 78,270)-(.09 * .076 * 78,270) \approx 5,400$. For Republicans: $(.074$ $* 46,753)-(.08 * .074 * 46,753) \approx 3,200$. Crossover percentage is drawn from exit polls conducted by Edison Media Research. If crossover is assumed to be 0 , a similar result holds.
} 
TABLE 4 Mitigating Bias from Habitual Voting

\begin{tabular}{lcccc}
\hline & ITT: All & ITT: Not Vote 2008 & TOT: All & TOT: Not Vote 2008 \\
\hline Preregistration & $0.03^{*}$ & $0.14^{*}$ & $0.08^{*}$ & $0.35^{*}$ \\
& $(0.01)$ & $(0.01)$ & $(0.03)$ & $(0.03)$ \\
Controls & Yes & Yes & Yes & Yes \\
Constant & 0.048 & 0.003 & 0.083 & 0.197 \\
& $(0.09)$ & $(0.10)$ & $(0.09)$ & $(0.11)$ \\
$\mathrm{N}$ & 36,790 & 26,466 & 36,790 & 26,466 \\
\hline
\end{tabular}

Note: Robust standard errors are in parentheses. Estimates are based on a 2-month window and a linear specification of the running variable. Controls: race (individual and county), party, gender, proportion of population that graduated high school (county), poverty (county), voter turnout (county), median age (county), and an indicator for the Democratic presidential party having a campaign office in the county. Coefficients for the controls are reported in the supporting information (see Table A3). ${ }^{*} \mathrm{p}<.05$.

practitioners. Here again we find that preregistration effects are remarkably consistent across these subgroups. The mobilizing effect for males $(7.3 \%)$ is similar to that for females $(7.4 \%)$. Moreover, preregistration's effect is similar for whites $(7.6 \%)$ and minorities $(8.0 \%)$. Despite each of these coefficient estimates being statistically distinct from 0 at the $5 \%$ level, none are statistically distinguishable from one another. In sum, along with having the virtue of raising overall turnout, preregistration has the advantage of doing so for a diverse set of young voters.

\section{Discussion}

Previous work has cast doubt on the ability of institutional reforms to increase turnout (Ansolabehere and Konisky 2006; Berinsky, Burns and Traugott 2001; Burden and Neiheisel 2013; Erikson 1981; Highton 1997; Keele and Minozzi 2013; Martinez and Hill 1999), with some evidence that some reforms actually depress turnout (Burden et al. 2014). In a noticeable departure, we find that preregistration laws are effective at increasing turnout among young voters. Using more compelling causal modeling approaches indicates that preregistration increases young voter turnout. These findings are robust to the data source, causal approach, and model specification considered. Moreover, the estimates of preregistration's effectiveness are widespread, similar for Republicans and Democrats, whites and minorities, and men and women.

Although the consistency of the observed patterns is compelling evidence that preregistration laws can increase youth turnout, there clearly remains more to understand about the reasons why this electoral reform is effective where so many others have failed. We have argued that preregistration leverages the contextual reinforcement of political campaigns and supporting institutions, including the schooling system. While a full exploration of these mechanisms is beyond the scope of this article, we can offer some initial empirical evidence in support of this theoretical perspective. The simple fact that the majority of preregistrations occur in an election context suggests the interaction of preregistration laws and the campaign environment is important. For example, in looking at all the preregistrations that occurred in Florida in the 2-year time period from November 2007 to November 2009 , we find that $77.7 \%$ occurred in the year before the 2008 election.

To examine the possible role of reinforcement by educational institutions, we take advantage of variation across Florida schools in the presentation of in-school voting demonstrations by county election officials. In these demonstrations, county officials go to high schools and explain the logistics of voting, show students a sample ballot and voting booth, and encourage them to vote. According to a 2012 survey of county election officials, $71 \%(48 / 67)$ of Florida counties engaged in voting demonstrations within county high schools. ${ }^{37}$ We estimated our model across counties with and without these voting demonstrations and find that the preregistration effect is 4.6 points higher in counties reporting they engaged in the demonstrations (see Table A9 in the supporting information). Counties without demonstrations see a preregistration effect of 0.072 , whereas counties with demonstrations see an effect of 0.118 . Coefficients are statistically distinct from 0 and statistically distinct from one another at the $5 \%$ level. This offers at least initial support

\footnotetext{
${ }^{37}$ Data are drawn from Florida's election-year survey of county election officials: http://election.dos.state.fl.us/reports/. In this survey, county officials responded to the question of whether their county "participate[d] in voting system demonstrations at high schools." Unfortunately, we know little about the exact content of the demonstrations or quality of coverage across high schools within a given county.
} 
to our theoretical perspective that evaluations of electoral reforms should consider the interaction of reforms with the broader institutional and contextual environment.

Recent research highlights the notion that electoral reforms cannot make individuals interested in politics, but perhaps it should also consider the possibility that such interest might not be as stable as sometimes suggested (Prior 2010), especially for young adults. Preregistration laws leverage variability in political interest by targeting young citizens when they are in school and during the increased excitement, motivation, and mobilization of political campaigns. This means, of course, that preregistration is not a solve-all because those who come of age outside of a campaign year are unlikely to take advantage of the policy. Nevertheless, preregistration appears to be an effective electoral reform to boost turnout for a sizable subset of young voters. These observed effects should be of interest not only to policy makers as they consider the potential of electoral reform, but also to scholars who might find possible lines of future research that marry the literature on campaign dynamics, education effects, and electoral institutions.

\section{Appendix: Florida Full Model Results}

\section{Table A1 Florida Regression Discontinuity Estimates, with Controls}

\begin{tabular}{|c|c|c|c|c|}
\hline & $\begin{array}{c}\text { ITT } \\
(2008) \\
\end{array}$ & $\begin{array}{c}\text { TOT } \\
(2008) \\
\end{array}$ & $\begin{array}{l}\text { ITT: Fixed Effects } \\
(2004 \text { and 2008) }\end{array}$ & $\begin{array}{c}\text { TOT: Fixed Effects } \\
\qquad(2008)\end{array}$ \\
\hline Preregistration (individual) & $\begin{array}{r}0.03^{*} \\
(0.01)\end{array}$ & $\begin{array}{r}0.08^{*} \\
(0.03)\end{array}$ & $\begin{array}{r}0.02^{*} \\
(0.01)\end{array}$ & $\begin{array}{r}0.08^{*} \\
(0.03)\end{array}$ \\
\hline Proximity to Ineligibility (individual) & $\begin{array}{c}-0.04 \\
(0.05)\end{array}$ & $\begin{array}{l}-0.03 \\
(0.04)\end{array}$ & $\begin{array}{c}-0.02 \\
(0.03)\end{array}$ & $\begin{array}{c}-0.03 \\
(0.04)\end{array}$ \\
\hline African American (individual) & $\begin{array}{r}0.08^{*} \\
(0.01)\end{array}$ & $\begin{array}{c}0.08^{*} \\
(0.01)\end{array}$ & $\begin{array}{c}0.03^{*} \\
(0.01)\end{array}$ & $\begin{array}{c}0.08^{*} \\
(0.01)\end{array}$ \\
\hline Hispanic (individual) & $\begin{array}{r}-0.04^{*} \\
(0.01)\end{array}$ & $\begin{array}{r}-0.04^{*} \\
(0.01)\end{array}$ & $\begin{array}{r}-0.05^{*} \\
(0.01)\end{array}$ & $\begin{array}{r}-0.04^{*} \\
(0.01)\end{array}$ \\
\hline Race Unknown (individual) & $\begin{array}{c}0.01 \\
(0.01)\end{array}$ & $\begin{array}{c}0.01 \\
(0.01)\end{array}$ & $\begin{array}{c}-0.01 \\
(0.01)\end{array}$ & $\begin{array}{c}0.02 \\
(0.02)\end{array}$ \\
\hline Minor Race (individual) & $\begin{array}{c}0.01 \\
(0.01)\end{array}$ & $\begin{array}{c}0.01 \\
(0.01)\end{array}$ & $\begin{array}{c}-0.01 \\
(0.01)\end{array}$ & $\begin{array}{c}0.01 \\
(0.01)\end{array}$ \\
\hline Democrat (individual) & $\begin{array}{r}-0.07^{*} \\
(0.01)\end{array}$ & $\begin{array}{r}-0.07^{*} \\
(0.01)\end{array}$ & $\begin{array}{r}-0.04^{*} \\
(0.01)\end{array}$ & $\begin{array}{r}-0.07^{*} \\
(0.01)\end{array}$ \\
\hline Minor Party (individual) & $\begin{array}{r}-0.13^{*} \\
(0.02)\end{array}$ & $\begin{array}{r}-0.13^{*} \\
(0.02)\end{array}$ & $\begin{array}{r}-0.13^{*} \\
(0.01)\end{array}$ & $\begin{array}{r}-0.13^{*} \\
(0.02)\end{array}$ \\
\hline Unaffiliated Party (individual) & $\begin{array}{r}-0.17^{*} \\
(0.01)\end{array}$ & $\begin{array}{r}-0.16^{*} \\
(0.01)\end{array}$ & $\begin{array}{r}-0.15^{*} \\
(0.01)\end{array}$ & $\begin{array}{r}-0.17^{*} \\
(0.01)\end{array}$ \\
\hline Female (individual) & $\begin{array}{c}0.10^{*} \\
(0.01)\end{array}$ & $\begin{array}{c}0.10^{*} \\
(0.01)\end{array}$ & $\begin{array}{c}0.11^{*} \\
(0.00)\end{array}$ & $\begin{array}{c}0.10^{*} \\
(0.01)\end{array}$ \\
\hline Unknown Gender (individual) & $\begin{array}{r}0.06^{*} \\
(0.02)\end{array}$ & $\begin{array}{r}0.06^{*} \\
(0.02)\end{array}$ & $\begin{array}{r}0.04^{*} \\
(0.01)\end{array}$ & $\begin{array}{r}0.05^{*} \\
(0.02)\end{array}$ \\
\hline \% High School Degree (county) & $\begin{array}{c}0.16 \\
(0.09)\end{array}$ & $\begin{array}{c}0.13 \\
(0.09)\end{array}$ & $\begin{array}{r}0.59^{*} \\
(0.05)\end{array}$ & - \\
\hline \% Poverty (county) & $\begin{array}{c}0.16 \\
(0.09)\end{array}$ & $\begin{array}{c}0.14 \\
(0.09)\end{array}$ & $\begin{array}{r}0.47^{*} \\
(0.06)\end{array}$ & - \\
\hline$\%$ Turnout (county) & $\begin{array}{r}0.63^{*} \\
(0.09)\end{array}$ & $\begin{array}{r}0.64^{*} \\
(0.09)\end{array}$ & $\begin{array}{c}0.33^{*} \\
(0.06)\end{array}$ & - \\
\hline Average Age (county) & $\begin{array}{c}-0.00 \\
(0.00)\end{array}$ & $\begin{array}{r}-0.01^{*} \\
(0.00)\end{array}$ & $\begin{array}{r}-0.004^{*} \\
(0.001)\end{array}$ & - \\
\hline
\end{tabular}


TABle A1 Florida Regression Discontinuity Estimates, with Controls

\begin{tabular}{|c|c|c|c|c|}
\hline & $\begin{array}{c}\text { ITT } \\
(2008)\end{array}$ & $\begin{array}{c}\text { TOT } \\
(2008)\end{array}$ & $\begin{array}{l}\text { ITT: Fixed Effects } \\
(2004 \text { and 2008) }\end{array}$ & $\begin{array}{c}\text { TOT: Fixed Effects } \\
(2008)\end{array}$ \\
\hline \% White (county) & $\begin{array}{r}-0.06^{*} \\
(0.02)\end{array}$ & $\begin{array}{r}-0.05^{*} \\
(0.02)\end{array}$ & $\begin{array}{r}-0.07^{*} \\
(0.02)\end{array}$ & - \\
\hline$\%$ African American (county) & $\begin{array}{c}0.24^{*} \\
(0.05)\end{array}$ & $\begin{array}{r}0.23^{*} \\
(0.05)\end{array}$ & $\begin{array}{c}0.12^{*} \\
(0.04)\end{array}$ & - \\
\hline Democratic Office (county) & $\begin{array}{r}0.02^{*} \\
(0.01)\end{array}$ & $\begin{array}{r}0.02^{*} \\
(0.01)\end{array}$ & $\begin{array}{c}0.01^{*} \\
(0.00)\end{array}$ & - \\
\hline Fixed Effects & No & No & Birthday & County \\
\hline Constant & $\begin{array}{c}0.05 \\
(0.09)\end{array}$ & $\begin{array}{c}0.08 \\
(0.09) \\
\end{array}$ & $\begin{array}{r}-0.02 \\
(0.06) \\
\end{array}$ & $\begin{array}{c}0.56^{*} \\
(0.08) \\
\end{array}$ \\
\hline $\mathrm{N}$ & 36,790 & 36,790 & 71,251 & 36,790 \\
\hline Adjusted $\mathrm{R}^{2}$ & 0.04 & 0.04 & 0.05 & 0.04 \\
\hline
\end{tabular}

Note: Dependent variable is whether or not an individual voted. Sample is those born within 6 months of eligibility to vote in the 2008 threshold, with a window of half that for the models estimated here. Robust standard errors are in parentheses. Bandwidth is about 2.5 months on either side of the cutoff. Proximity to eligibility is modeled linearly. Column 3 includes data from the same window of those eligible/ineligible in 2004 to estimate the date of birth fixed effect. Column 4 eliminates the county-level controls because of their colinearity with the county fixed effects. ${ }^{*} \mathrm{p}<.05$.

\section{References}

Alvarez, R. Michael, Delia Bailey, and Jonathan Katz. 2008. "The Effect of Voter Identification Laws on Turnout." California Institute of Technology Social Science Working Paper (1267R).

Angrist, Joshua D., and Jörn-Steffen Pischke. 2008. Mostly Harmless Econometrics: An Empiricist's Companion. Princeton, NJ: Princeton University Press.

Ansolabehere, Stephen, Eitan Hersh, and Kenneth Shepsle. 2012. "Movers, Stayers, and Registration: Why Age Is Correlated with Registration in the U.S." Quarterly Journal of Political Science 7(4): 333-63.

Ansolabehere, Stephen, and David M. Konisky. 2006. "The Introduction of Voter Registration and Its Effect on Turnout." Political Analysis 14(1): 83-100.

Ashenfelter, Orley, and David Card. 1985. "Using the Longitudinal Structure of Earnings to Estimate the Effect of Training Programs." Review of Economics and Statistics 67(4): 648-60.

Atkeson, Lonna R., Lisa A. Bryant, Thad E. Hall, Kyle Saunders, and Michael Alvarez. 2010. "A New Barrier to Participation: Heterogeneous Application of Voter Identification Policies." Electoral Studies 29(1): 66-73.

Bennion, Elizabeth A., and David W. Nickerson. 2011. "The Cost of Convenience: An Experiment Showing Email Outreach Decreases Voter Registration.” Political Research Quarterly 64(4): 858-69.

Berinsky, Adam J., Nancy Burns, and Michael W. Traugott. 2001. "Who Votes by Mail? A Dynamic Model of the Individual-Level Consequences of Voting-by-Mail Systems." Public Opinion Quarterly 65(2): 178-97.

Bloom, Howard S. 1984. "Accounting for No-Shows in Experimental Evaluation Designs." Evaluation Review 8(2): 22546.
Brady, Henry, and John McNulty. 2011. "Turning Out to Vote: The Costs of Finding and Getting to the Polling Place." American Political Science Review 105(1): 115-34.

Brians, Craig Leonard, and Bernard Grofman. 2001. "Election Day Registration's Effect on U.S. Voter Turnout." Social Science Quarterly 82(1): 170-83.

Bryan, Christopher J., Gregory M. Walton, Todd Rogers, and Carol S. Dweck. 2011. "Motivating Voter Turnout by Invoking the Self." Proceedings of the National Academy of Sciences 108(31): 12653-56.

Burden, Barry C., David T. Canon, Kenneth R. Mayer, and Donald P. Moynihan. 2014. "Election Laws, Mobilization, and Turnout: The Unanticipated Consequences of Election Reform." American Journal of Political Science 58(1): 95108.

Burden, Barry C., and Jacob R. Neiheisel. 2013. "Election Administration and the Pure Effect of Voter Registration on Turnout.” Political Research Quarterly 66(1): 77-90.

Burnham, Walter D. 1987. “The Turnout Problem.” In Elections American Style, ed. A. James Reichley. Washington, DC: Brookings Institution, 97-133.

Butler, David, and Donald Stokes. 1974. Political Change in Britain: The Evolution of Electoral Choice. London: Macmillan.

Cain, Bruce E., and Ken McCue. 1985. "The Efficacy of Registration Drives." Journal of Politics 47(4): 1221-30.

Cherry, Ceridwen. 2011. "Increasing Youth Participation: The Case for a National Voter Preregistration Law." University of Michigan Journal of Law Reform 45: 481-515.

Eggers, Andrew C., and Jens Hainmueller. 2009. "MPs for Sale? Returns to Office in Postwar British Politics." American Political Science Review 103(4): 513-32.

Erikson, Robert S. 1981. "Why Do People Vote? Because They Are Registered." American Politics Research 9(3): 259-76. 
Erikson, Robert S., and Lorraine C. Minnite. 2009. "Modeling Problems in the Voter Identification-Voter Turnout Debate." Election Law Journal 8(2): 85-101.

Ferraz, Claudio, and Frederico Finan. 2009. "Motivating Politicians: The Impacts of Monetary Incentives on Quality and Performance." National Bureau of Economic Research Working Paper (14906).

Fitzgerald, Mary. 2005. "Greater Convenience But Not Greater Turnout: The Impact of Alternative Voting Methods on Electoral Participation in the United States." American Politics Research 33(6): 842-67.

Fowler, James H. 2006. "Habitual Voting and Behavioral Turnout." Journal of Politics 68(2): 335-44.

Freedman, Paul, Michael Franz, and Kenneth Goldstein. 2004. "Campaign Advertising and Democratic Citizenship." American Journal of Political Science 48(4): 723-41.

Gelman, Andrew, and Jennifer Hill. 2007. Data Analysis Using Regression and Multilevel/Hierarchical Models. New York: Cambridge University Press.

Guryan, Jonathan. 2004. "Desegregation and Black Dropout Rates." American Economic Review 94(4): 919-43.

Hanmer, Michael J. 2009. Discount Voting: Voter Registration Reforms and Their Effects. New York: Cambridge University Press.

Hanmer, Michael J., Won-Ho Park, Michael W. Traugott, Richard G. Niemi, Paul S. Herrnson, Benjamin B. Bederson, and Frederick C. Conrad. 2010. "Losing Fewer Votes: The Impact of Changing Voting Systems on Residual Votes." Political Research Quarterly 63(1): 129-42.

Herrnson, Paul S., Richard G. Niemi, Michael J. Hanmer, Peter L. Francia, Benjamin B. Bederson, Frederick G. Conrad, and Michael W. Traugott. 2008. "Voters' Evaluations of Electronic Voting Systems Results from a Usability Field Study." American Politics Research 36(4): 580-611.

Herron, Michael C., and Daniel A. Smith. 2012. "Souls to the Polls: Early Voting in Florida in the Shadow of House Bill 1355." Election Law Journal 11(3): 331-47.

Highton, Benjamin. 1997. "Easy Registration and Voter Turnout." Journal of Politics 59(2): 565-75.

Highton, Benjamin. 2000. "Residential Mobility, Community Mobility, and Electoral Participation." Political Behavior 22(2): 109-20.

Hillygus, D. Sunshine, and Todd G. Shields. 2008. The Persuadable Voter: Wedge Issues in Presidential Campaigns. Princeton, NJ: Princeton University Press.

Imbens, Guido, and Karthik Kalyanaraman. 2012. "Optimal Bandwidth Choice for the Regression Discontinuity Estimator." Review of Economic Studies 79(3): 933-59.

Jacob, Brian A., and Lars Lefgren. 2004. "Remedial Education and Student Achievement: A Regression-Discontinuity Analysis." Review of Economics and Statistics 86(1): 226-44.

Karp, Jeffrey A., and Susan A. Banducci. 2000. "Going Postal: How All-Mail Elections Influence Turnout." Political Behavior 22(3): 223-39.

Keele, Luke, and William Minozzi. 2013. "How Much Is Minnesota Like Wisconsin? Assumptions and Counterfactuals in Causal Inference with Observational Data." Political Analysis 21(2): 193-216.
Knack, Stephen. 1995. "Does Motor Voter Work? Evidence from State-Level Data.” Journal of Politics 57(3): 796-811.

Kousser, Thad, and Megan Mullin. 2007. "Does Voting by Mail Increase Participation? Using Matching to Analyze a Natural Experiment." Political Analysis 15(4): 428-45.

Lee, David S., and David Card. 2008. "Regression Discontinuity Inference with Specification Error.” Journal of Econometrics 142(2): 655-74.

Lee, David S., and Thomas Lemieux. 2010. "Regression Discontinuity Designs in Economics.” Journal of Economic Literature 48(2): 281-355.

Leighley, Jan E., and Jonathan Nagler. 2013. Who Votes Now? Demographics, Issues, Inequality, and Turnout in the United States. Princeton, NJ: Princeton University Press.

Lijphart, Arend. 1997. "Unequal Participation: Democracy's Unresolved Dilemma." American Political Science Review 91(1): 1-14.

Manski, Charles F. 1990. "Nonparametric Bounds on Treatment Effects." American Economic Review 8(2): 319-23.

Martinez, Michael D., and David Hill. 1999. "Did Motor Voter Work?” American Politics Research 27(3): 296-315.

McCrary, Justin. 2008. "Manipulation of the Running Variable in the Regression Discontinuity Design: A Density Test." Journal of Econometrics 142(2): 698-714.

McDonald, Michael P. 2008. "Portable Voter Registration.” Political Behavior 30(4): 491-501.

McDonald, Michael P. 2009. "Voter Preregistration Programs." Washington, DC: Making Voting Work Project.

McDonald, Michael P., and Matthew Thornburg. 2010. "Registering the Youth through Voter Preregistration." New York University Journal of Legislation and Public Policy 13: 551-72.

Meredith, Marc. 2009. "Persistence in Political Participation." Quarterly Journal of Political Science 4(3): 187-209.

Mycoff, Jason D., Michael W. Wagner, and David C. Wilson. 2009. "The Empirical Effects of Voter-ID Laws: Present or Absent?” PS: Political Science \& Politics 42(1): 12126.

Neiheisel, Jacob R., and Barry C. Burden. 2012. "The Impact of Election Day Registration on Voter Turnout and Election Outcomes." American Politics Research 40(4): 63664.

Niemi, Richard G., Michael J. Hanmer, Benjamin B. Bederson, Frederick G. Conrad, and Michael W. Traugott. 2009. Voting Technology: The Not-So-Simple Act of Casting a Ballot. Washington, DC: Brookings Institution Press.

Niemi, Richard G., and Jane Junn. 2005. Civic Education: What Makes Students Learn. New Haven, CT: Yale University Press.

Olken, Benjamin A. 2010. "Direct Democracy and Local Public Goods: Evidence from a Field Experiment in Indonesia." American Political Science Review 104(2): 243-67.

Plutzer, Eric. 2002. "Becoming a Habitual Voter: Inertia, Resources, and Growth in Young Adulthood." American Political Science Review 96(1): 41-56.

Ponoroff, Christopher, and Wendy R. Weiser. 2010. Voter Registration in a Digital Age. New York: Brennan Center for Justice. 
Powell, G. Bingham. 1986. "American Voter Turnout in Comparative Perspective." American Political Science Review 80(1): 17-43.

Prior, Markus. 2010. "You've Either Got It or You Don't? The Stability of Political Interest over the Life Cycle." Journal of Politics 72(3): 747-66.

Timpone, Richard J. 1998. "Structure, Behavior, and Voter Turnout in the United States." American Political Science Review 92(1): 145-58.

Trochim, William. 1984. Research Design for Program Evaluation: The Regression Discontinuity Approach. Beverly Hills, CA: Sage.

U.S. Congress. 2004. U.S. Congressional Record. 108th Congress. Vol. 150, No. 103.

Vercellotti, Timothy, and David Anderson. 2006. "Protecting the Franchise, or Restricting It." Presented at the American Political Science Association Annual Meeting, Philadelphia.

Wolfinger, Raymond E., and Steven J. Rosenstone. 1980. Who Votes? New Haven, CT: Yale University Press.

\section{Supporting Information}

Additional Supporting Information may be found in the online version of this article at the publisher's website:

Table A1. Bracketing Bias (Probit)

Table A2. Balance at the Eligibility to Vote Margin

Table A3. Mitigating Habitual Bias

Table A4. Florida RD Estimates (Probit)

Table A5. Florida RD Estimates (no controls)

Table A6. Florida RD Estimates (optimal band.)

Table A7. Florida RD Estimates (alternate specifications of running)

Table A8. Heterogeneities in Preregistration's Impact

Table A9. Preregistration Mechanisms (voting systems demonstrations)

Figure A1. McCrary Density Check

Figure A2. Preregistration by Date 